\title{
Relationships Between Health and Environmental Information on the Willingness to Pay for Functional Foods: The Case of a New Aloe Vera Based Product
}

\author{
Elena Castellari ${ }^{1}$, Elena Claire Ricci ${ }^{2}\left(\mathbb{D}\right.$, Stefanella Stranieri ${ }^{3}$, , Stéphan Marette ${ }^{4}$, \\ Martina Sarnataro ${ }^{1}$ and Claudio Soregaroli ${ }^{1}$ \\ 1 Department of Agri-Food Economics, Università Cattolica del Sacro Cuore, Piacenza, Via Emilia Parmense, \\ 84, 29122 Piacenza, Italy; elena.castellari@unicatt.it (E.C.); m.sarnataro123@gmail.com (M.S.); \\ claudio.soregaroli@unicatt.it (C.S.) \\ 2 Department of Business Administration, Università degli Studi di Verona, Via Cantarane 24, 37129 Verona, \\ Italy; elenaclaire.ricci@univr.it \\ 3 Department of Environmental Science and Policy, Università degli Studi di Milano, Via Celoria 2, \\ 20133 Milano, Italy \\ 4 UMR Économie Publique, INRA, Université Paris-Saclay, F-78850 Grignon, France; \\ stephan.marette@agroparistech.fr \\ * Correspondence: stefanella.stranieri@unimi.it; Tel.: +39-0250316460
}

Received: 29 September 2019; Accepted: 11 November 2019; Published: 15 November 2019

\begin{abstract}
There is an increasing interest in healthy and sustainable product characteristics. Consumers determine their dietary intake and frame production systems with their choices. However, little is known about the relationships between health and environmental information in influencing these choices, especially when considering functional foods. This study assessed the influence of health-related and environmental-friendliness-related product information on the willingness to pay (WTP) for functional foods. To this end, a WTP elicitation experiment was set up using a jam-like fruit compote enriched with Aloe vera gel. Participants were provided with different messages related to the health and environmental benefits of Aloe vera products, and were also asked to taste the product. Results indicated that providing new information significantly increased the WTP for the enriched compote. This increase was significant for both health and environmentally based benefits, with the health message leading to a higher WTP. Combining health and environmental messages produced an additive effect on WTP which was independent of the sequential order in which the two messages were given. Results contrasted the view that health messages are the main drivers of WTP, and open a broader range of communication in terms of marketing strategies and sustainable policy objectives.
\end{abstract}

Keywords: food choices; functional food; health information; environmental information; choice experiment; sustainability

\section{Introduction}

Consumers are increasingly interested in healthy and sustainable product characteristics when buying food [1]. Most consumers have concerns about environmental issues and look for sustainable products with environmentally friendly characteristics which can also positively affect their health [2,3].

In recent decades, the prevalence of food with nutritionally enriched characteristics and functional ingredients aimed at improving human wellbeing has increased considerably [4]. Functional food captures this trend of food demand by offering products that impact positively on human health.

The market for functional food is steadily increasing, even if making an estimate of the market dimension for these products is complicated, mainly because of the lack of a common, internationally 
recognized definition of such products [5]. In Europe, functional food is defined as "natural or processed foods that contain known or unknown biologically active compounds which, in defined, effective non-toxic amounts, provide a clinically proven and documented health benefit for the prevention, management, or treatment of chronic disease" [6]. Diplock et al. [7] considered a broader definition by considering products to be functional when it has been satisfactorily proven that they positively affect human health and wellbeing beyond nutritional effects. Moreover, Poulsen [8] introduced an even broader definition, identifying four characteristics that could cause a product to be considered functional: (i) the enrichment of food with a substance which is already part of the product; (ii) the substitution of a nutrient with another one; (iii) the adding of a new substance in the product; or (iv) the elimination of a component of the product.

Plant food supplements like aloe-based food products can be considered products with functional characteristics according to the above definitions. Plant food supplements are foodstuffs with a high concentration of botanical preparations that have nutritional or physiological effects, alone or in combination with vitamins, minerals, and other substances which are not plant-based.

Literature to date has explored the market response of functional food mainly by investigating the factors influencing consumer acceptance of such products [9-11]. This includes socioeconomic characteristics such as gender [12-14], age [15,16], knowledge [17-19], and lifestyles [5], as well as cognitive and attitudinal drivers [5,17,20-24] including cultural factors [25], and the role of beliefs [26]. In addition, some quality product characteristics, such as price, convenience, and taste [27] have been found to influence consumer acceptance for functional foods.

A relevant body of literature has also explored the effect of labeled health information on consumer preferences and willingness to use novel foods with functional characteristics. Most of the empirical results have highlighted a positive influence of health claims on the evaluation and choice of functional foods $[28,29]$. Other studies have concentrated their attention on the information most able to enhance consumer response to health claims for functional foods, highlighting how physiology-related health benefits [30], or health benefits more generally [24,31], are positively impacting motivation to purchase or are evaluated better than nutrition claims or disease-risk claims [17]. At the same time, the negative trade-off between healthy characteristics and taste seems to reduce the acceptance of functional foods over time [27].

To the best of our knowledge, there is currently a gap in the evaluation of other types of information, apart from health-based, on consumer intention to use functional foods. For example, the effect of information about the environmentally sustainable attributes of such products has received only limited attention, even if consumers have been shown to have interest in such characteristics in food products [32-34]. Moreover, there is also little evidence on the possible synergic or additive effects of using different types of information on the willingness to pay for products with functional characteristics. Only a recent study conducted by Goetzke et al. [35] has studied the effect of healthy consumer lifestyle on the consumption of organic and functional food. More generally, it appears that the impact of environmental information on food consumption has been much less researched compared to health-related information and the combination of these two types of information has garnered very little attention [36].

Study on the effects of health-related and environmental sustainability information is particularly important as it contributes to the knowledge that could favor a transition toward healthier diets and sustainable food systems [37]. This is a widely recognized goal among scientists, institutions, and the public. Information influences consumer demand, and this demand decides the healthiness of diets and frames production systems $[38,39]$. There is a growing understanding of the interrelationships between diet, health, and the environment [40]. Actions in this direction are already visible. For example, as highlighted by Hoek et al. [41], although dietary guidelines worldwide are mostly focused on health, some governmental bodies are starting to introduce indications from both environmental and nutritional science to frame new guidelines. 
On the basis of the above research gaps, the aims of the present paper were: (i) to assess the influence of health-related and environmental friendliness product information on the willingness to pay for functional foods; (ii) to empirically estimate the presence of possible synergic or additive effects of health and environmental-friendliness-related information on the overall evaluation of functional foods.

In our empirical analysis we referred to a unique, jam-like, aloe-based fruit compote that has not been commercialized. The health characteristics of this product relate to the absence of added sugar and to a high concentration of Aloe vera. The gel has a wide array of pharmacological attributes including: anti-viral, anti-bacterial, laxative, protection against radiation, anti-oxidant, anti-inflammation, anticancer, anti-diabetic, anti-allergenic, and immuno-stimulation activities. As far as the food industry is concerned, the potential use of Aloe vera gel has mainly focused on the development of functional foods due to its beneficial properties in treating constipation, coughs, diabetes, headaches, arthritis and immune system deficiencies, and digestive effects [42]. The environmentally friendly properties of such products relate to the sustainable cultivation practices of Aloe vera, as the plant can grow in arid and marginal areas without the need for chemicals and with a very limited water consumption.

The paper is organized as follows: Section 2 describes the experimental design and the data analysis procedure, Section 3 presents the results, and Section 4 discusses the results in the context of the available literature, and highlights suggestions for future research and study limitations.

\section{Materials and Methods}

\subsection{Sample and Products}

The experiment was conducted across several sessions in June-July 2017 in Italy. We interviewed 115 respondents in groups of about 15 each, but given the incomplete replies of three participants, the analysis was carried out on a sample of 112. Participants were all aware of the experiment and agreed to be included in the study before participating. Data were treated anonymously and used for research purposes only, with no way of connecting responses to specific individuals.

The experiment focused on two products: (1) a $250 \mathrm{~g}$ jar of fruit compote made with Aloe vera gel $(40 \%)$, Sultanina grape (30\%), plums (27.5\%), and orange peel (2.5\%); (2) a $250 \mathrm{~g}$ jar of fruit compote with the same composition as the previous one, but with the Aloe vera gel replaced with pectin. Pectin was used as it conferred a similar texture to the final product and minimally altered the taste of the product with respect to the other ingredients.

The aloe-based fruit compote was developed by university students taking part in the Ecothrophelia project as an innovative and eco-friendly product called "AloeSpoon", completely new and original in its category, as at the time the experiment took place, no jam or jam-like products with at least $40 \%$ Aloe vera gel concentration were available on the market. AloeSpoon is a jam-like fruit compote product that could possibly be assigned to the functional food category thanks to the health benefits conferred by the presence of aloe. The product, as law requires (art. 2, para. 4, Legislative Decree 20 February 2004, no. 50), belongs to the category of "fruit compote" because of its fruit content, which is equal to or higher than $65 \%$. More information about AloeSpoon is provided in Appendices A and B.

For the purpose of the experiment, what was relevant was the ability to control ceteris paribus for the presence of Aloe vera gel. Both products were made in the university laboratory of the Department for Sustainable Food Process of the Università Cattolica del Sacro Cuore, Italy, and were provided to the authors for this experiment. The two fruit compotes were presented using the same type of glass jar, no brand was indicated, and they were visually indistinguishable from each other. Therefore, the only differences perceived by the participants were in the information provided in the experimental design and in the product tasting. 


\subsection{Research Aims and Experimental Design}

This study evaluated the willingness to pay (WTP) for attributes provided by a new (aloe-based) product, AloeSpoon, and the relevance of the information provided. More precisely, the aim of this study was to measure consumers' WTP for the health and environmental attributes provided by the fruit compote, and to evaluate whether the WTP changed when consumers were informed of the health benefits and of the environmentally friendly characteristics of the product. Moreover, since the product had not been commercialized at the time of the experiment, consumers were not familiar with its taste. This allowed assessment of the possible effect of the Aloe vera gel in changing the WTP as a result of product tasting. As explained in Figure 1, product tasting was randomly assigned to two groups (G3 and G4) with different information schemes. The tasting took place at the beginning of the experiment, during the first elicitation round (where no information was provided).

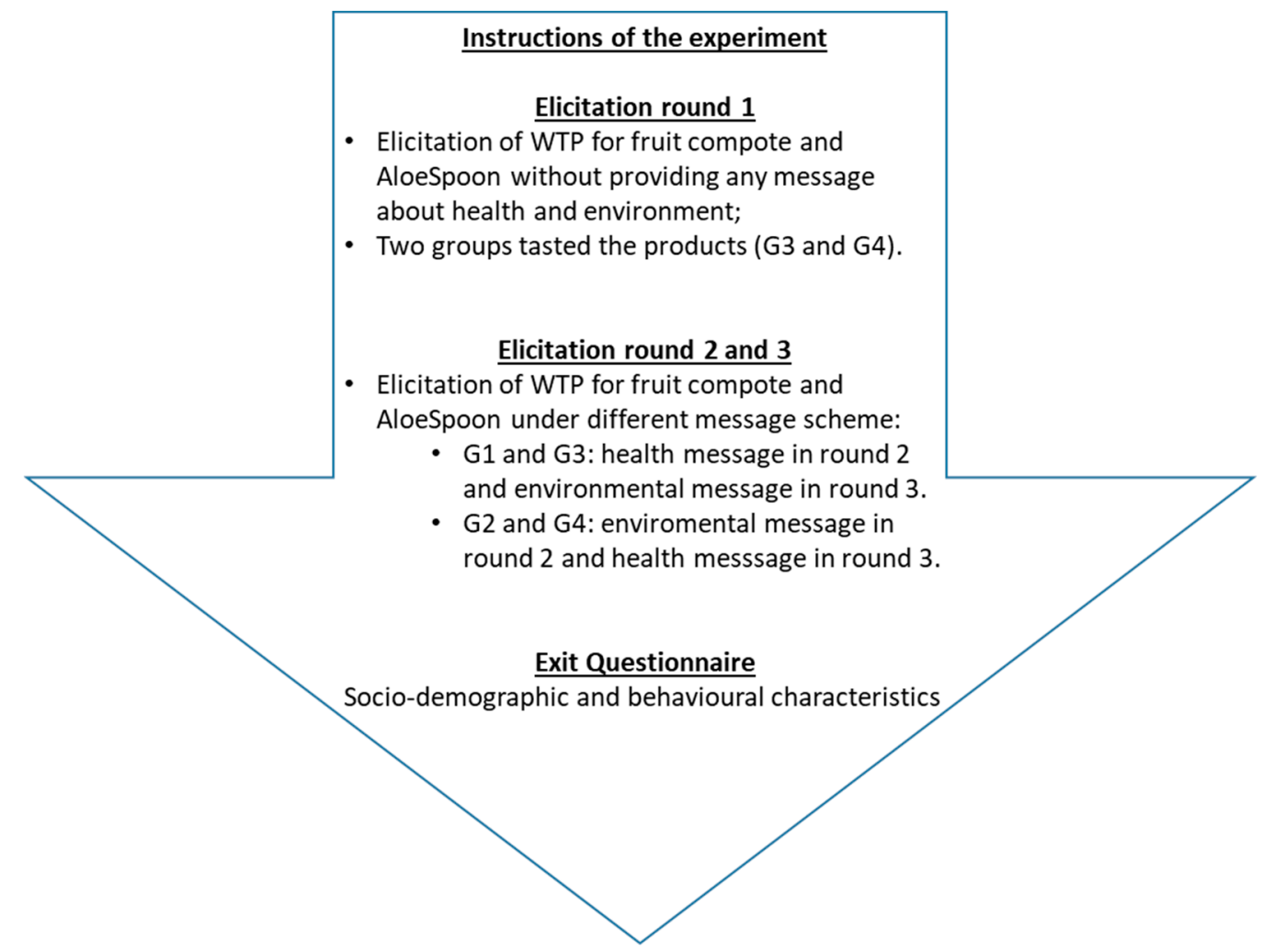

Figure 1. Timeline of the experiment.

The hypotheses we aimed to test were as follows:

Hypothesis 1. Consumers assign a higher value to the product enriched with Aloe vera, i.e., they show a higher WTP for such a product compared to its fruit-only counterpart;

Hypothesis 2. Providing additional product information on the health-related properties of Aloe vera and/or on the environmental impacts of its production affects the WTP;

Hypothesis 3. A health message directed at highlighting the private benefits for consumers is more effective than one about environmental sustainability, which is associated with public benefits, i.e., the health message induces a greater increase in WTP;

Hypothesis 4. The two types of information interact and impact the size of their effects; 
Hypothesis 5. The ordering of the information provided, i.e., whether the health-related or the environmental message is provided first, impacts the evaluation of the product (manifested by different WTP values).

To this aim, the questionnaire consisted of different rounds of WTP elicitations using a multiple price list (MPL) approach. The MPL approach relies on eliciting WTP asking to the participants their willingness to buy a specific product in an array of ordered prices ranging from a maximum to a minimum. For each price the subject is asked to indicate his willingness to buy indicating "yes", "no" or "maybe". The WTP results on the value where the subject switch from "yes" to "no" or "maybe". In case the subject answer to any price of the array either always "yes" or always "no" or "maybe", the WTP corresponds either to the maximum or to the minimum of the listed prices. For a further explanation of the MPL and its applications please refer to Andersen et al. [43].

The study was conducted in accordance with the principles of the Declaration of Helsinki. At the beginning of the experiment, initial explanations were read, and participants decided whether they wanted to provide their consent and thus agree to take part in the study. They were informed that all of their replies were anonymous, since they were identified only by a number. Participants were asked to indicate choices as if they were in a supermarket. It was clarified that there were no "good" or "bad" replies, so they were strongly suggested to freely indicate choices reflecting their preferences.

The framing of the experiment in its timeline is illustrated in Figure 1. Following Castellari et al. [44], after providing instructions for the experiment, the first section of WTP elicitation was carried out without any message related to the health or environmental benefits of Aloe vera. For this first round, instructions about the experiment were given, with only a few indications describing each product which were basically focused on the composition of the fruit compote.

The health and environmental messages were written after studying articles from the nutrition, agronomic, and environmental fields. The messages were relatively short, because previous works have underlined the benefit of providing a concise message when conveying complex information [45]. The messages provided were the following:

(a) Health-related message about the benefits of Aloe vera consumption

"Aloe gel has been used for centuries for its healing and therapeutic properties. Frequent use of aloe-based foods brings benefits to health. The gel has anti-viral, anti-bacterial, anti-oxidant, anti-inflammatory, anti-diabetic, anti-allergic, immune- stimulatory, and wetting and wound healing properties, and burn action. It is also used to support the health of the digestive tract. The use of aloe gel in the food industry is mainly focused on the development of functional foods. Thanks to its beneficial properties, it is mainly used in the treatment of constipation, cough, diabetes, migraine, arthritis, and immune system deficiency. Aloe-based products are suitable for consumers of all ages and offer a diverse range of health-related properties".

\section{(b) Environmental message about the environmentally friendly characteristics of Aloe vera}

"Aloe vera is an evergreen, xerophytic, greasy plant that has a tissue in the leaves allowing it to store a high water content and to survive in dry regions with reduced rainfall. Thus, it grows and can be cultivated even in arid and/or marginal areas without the need for chemicals, and hence with a highly sustainable agricultural process. It follows, therefore, that the cultivation of aloe has no negative effects on the environment".

The layout of these messages was precisely controlled by equally varying their order across four different groups of participants (Group1 (G1), Group 2 (G2), Group 3 (G3), and Group 4 (G4). Two groups started with the health-related message preceding the environmental message (G1 and G3), and two other groups started with the environmental message followed by the health-related message (G2 and G4). Furthermore, two of these groups tasted the products during the first round (G3 and G4). Participants were randomly assigned to one of the four groups (G1, G2, G3, G4). (For a clearer picture of the survey structure, refer to Table A2 in Appendix A). 
At the end of the third round, participants were asked to fill in a questionnaire aimed at identifying the consumer in terms of sociodemographic characteristics. They were asked to answer general questions concerning their age, gender, job type, family composition, monthly income, purchasing habits, and their previous knowledge about Aloe vera and Aloe-vera-based products.

\subsection{Elicitation Mechanism}

A multiple price list (payment card) was used to elicit WTP for each product. At the beginning of each round, participants were asked to indicate whether they would be willing to buy the product displayed for prices varying from $€ 2.00$ to $€ 18.00$ per unit. Research for reference prices was mostly carried out online, since aloe-based products are not usually sold in hypermarkets or large retail chain shops. Price research was also carried out in specialty stores and pharmacies. The multiple price list was characterized by increments of 50 cents between successive prices. For each price, participants were asked to select either "yes", "no", or "maybe" regarding their purchase willingness. For each product and each round of choice $R$, with $R=\{1 \ldots 3\}$, the WTP was determined by taking the highest price linked to a "yes" choice (with the next highest price on the paper sheet implying a reply "no" or "maybe"). If a participant replied only "no" or "maybe" to each line, the selected WTP was taken as equal to $€ 2.00$. If a participant only replied "yes" to each line, the selected WTP was taken as equal to $€ 18.00$.

The multiple price list method is a direct survey category which allows consumers to be provided with a product's description as well as information about its use and benefits. The use of this experimental method has several advantages: First, participants are able to focus on the product attributes rather than just on price. Second, they perceive their role less heavily, since they have some information to rely on. Moreover, participants can better judge the product's price based on the data provided. Finally, it is relatively easy for subjects to see that truthful revelation is in their best interests: If the subject believes that their responses have no effect on which row is chosen, then the task collapses to a binary choice in which the subject gets what they want if they answer truthfully [46].

Furthermore, the MPL has several attractive characteristics as an elicitation procedure since it is relatively easy to explain to subjects and to implement.

However, some possible disadvantages can be associated with the use of MPL. Firstly, MPL only elicits WTP valuations at intervals instead of "point" estimates [43]. In this experiment, we adopted a $€ 0.5$ interval in order to provide an adequate degree of precision for the WTP elicitation.

Secondly, subjects can switch back and forth from row to row, implying potentially inconsistent valuations [43]. This problem was not consistent with the way the consumers were surveyed in this study. Indeed, papers containing different kinds of information were given to consumers separately, in sequential steps.

Lastly, MPL could be susceptible to framing effects, as subjects are drawn to the middle of the ordered table irrespectively of their true values [43]. This can be controlled by changing the price list boundaries; however, we did not do this in the current study [43]. Further analyses by Anderson et al. [46] indicate that multiple price lists perform relatively well, obtaining precise product valuations that are also robust to framing effects.

\subsection{Sample Description}

The final sample analyzed in the experiment was made up of 112 respondents (Table 1). Women represented $60 \%$ of the sample, while $40 \%$ were men. Of the respondents, $22 \%$ of respondents were younger than 30 years of age, $30 \%$ were between 30 and 40 years of age, and $47 \%$ of the respondents were older than 40 years. A total $36 \%$ of the sample had an education up to high school, $32 \%$ had obtained a bachelor's-level degree, and $46 \%$ had reached a higher level of education. 
Table 1. Sample description.

\begin{tabular}{|c|c|c|c|}
\hline Variable Name & Variable Definition & Frequency & Percentage \\
\hline \multirow[t]{2}{*}{ male } & $1=$ if respondent $=$ male $; 0=$ otherwise & 45 & $40 \%$ \\
\hline & & 67 & $60 \%$ \\
\hline younger & $1=$ if repondent age $<30$ years old; $0=$ otherwise & 25 & $22 \%$ \\
\hline adult & $\begin{array}{c}1=\text { if respondent was between } 30-40 \text { years old; } \\
0=\text { otherwise }\end{array}$ & 34 & $30 \%$ \\
\hline older & $\begin{array}{c}1 \text { = if respondent was more than } 40 \text { years old; } \\
0=\text { otherwise }\end{array}$ & 53 & $47 \%$ \\
\hline middle school & $\begin{array}{c}1=\text { if the respondent's maximum level of education } \\
\text { was middle school; } 0=\text { otherwise }\end{array}$ & 3 & $3 \%$ \\
\hline diploma & $\begin{array}{c}1=\text { if the respondent's maximum level of education } \\
\text { was high school; } 0=\text { otherwise }\end{array}$ & 26 & $23 \%$ \\
\hline bachelor & $\begin{array}{c}1=\text { if the respondent's maximum level of education } \\
\text { was a bachelor's degree; } 0=\text { otherwise }\end{array}$ & 32 & $29 \%$ \\
\hline university & $\begin{array}{c}1=\text { if respondent had a university degree higher than } \\
\text { bachelor; } 0=\text { otherwise }\end{array}$ & 51 & $46 \%$ \\
\hline 1_income & $\begin{array}{l}1=\text { if household monthly income was less than } \\
\qquad 2000,0=\text { otherwise }\end{array}$ & 31 & $28 \%$ \\
\hline m_income & $\begin{array}{l}1=\text { if household monthly income was between } \\
\qquad 2000-5000 ; 0=\text { otherwise }\end{array}$ & 65 & $58 \%$ \\
\hline $\mathrm{h} \_$income & $\begin{array}{l}1=\text { if household monthly income was more than } \\
\qquad 5000,0=\text { otherwise }\end{array}$ & 16 & $14 \%$ \\
\hline \multirow[t]{2}{*}{ member } & $\begin{array}{c}1=\text { if size of family was up to three members; } \\
\qquad 0=\text { otherwise }\end{array}$ & 69 & $62 \%$ \\
\hline & & 43 & $38 \%$ \\
\hline \multirow[t]{2}{*}{ unemployed } & $1=$ if respondent was unemployed $; 0=$ otherwise & 15 & $5 \%$ \\
\hline & & 321 & $95 \%$ \\
\hline \multirow[t]{2}{*}{ knowledge } & $1=$ if respondent knew about Aloe vera $; 0=$ otherwise & 246 & $73 \%$ \\
\hline & & 90 & $27 \%$ \\
\hline
\end{tabular}

These distributions indicate that globally, the sample might have slightly favored consumer segments more interested in the nutritional and environmental aspects of food (for example, for gender and education levels). However, having included such variables in the analyses controlled for possible effects related to sample representitaveness.

\subsection{Data Analysis}

Data analysis included three steps. A first, exploratory step in which descriptive statistics were analyzed was done to provide an initial indication of how consumer preferences changed in the different treatments and rounds.

We then adopted inferential tools to investigate the role of information provision and other variables on consumer willingness to pay. More specifically, we used two random effects Tobit regression models to evaluate whether there was an increased willingness to pay for the compote enriched with Aloe vera and whether, and to what extent, this willingness to pay was affected by information provision regarding the health benefits of Aloe vera, information provision about the low environmental impacts of Aloe vera, or individual socio-demographic characteristics. The choice of the Tobit model was related to the fact that our data was left-censored at $€ 2$ and right-censored at $€ 18$ because of the experimental design. The random effect was associated to individuals and it was 
introduced to model possible positive dependencies among answers by the same individuals induced by individual specific preferences toward fruit compotes. The dataset indeed included six answers by each individual, given that answers were pooled for the elicitation round (Round 1 to 3 ). In detail, we estimated the model as follows:

$$
\begin{gathered}
W T P_{R i}^{*}=\beta_{0}+\beta_{1} X_{R}+\beta_{2} X_{i}+v_{i}+\epsilon_{R i} \\
W T P_{R i}=W T P_{R i}^{*} \text { if } 2<W T P^{*}<18 \\
W T P_{R i}=2 \text { if } W T P^{*}{ }_{R i} \leq 2 \\
W T P_{R i}=18 \text { if } W T P^{*}{ }_{R i} \geq 18
\end{gathered}
$$

where $\beta_{0}$ is the intercept, $\beta_{1}$ is a vector of a parameter associated with the experimental design variables (related to the presence of Aloe vera, the information provided, and tasting of the product), $X_{R}$ is the vector of dummy variables coding the experimental design, $\beta_{2}$ is a vector of a parameter associated with individual characteristics (age, gender, education, income, and occupation), $X i$ is the vector of regressors associated with the individual sociodemographic characteristics, $v_{i}$ is the individual specific random effect, and $\epsilon_{R i}$ is the error term.

More specifically, the two estimated models differed in how we modeled the experimental design. In the first model, $X_{R}$ was a vector of dummy variables indicating the presence of Aloe vera (aloe), the provision of a health-related message for the fruit-only/conventional compote ( $h$ _conv) or for the Aloe vera compote ( $\mathrm{h} \_$aloe), and the provision of an environmental-friendliness-related message for the fruit-only/conventional compote (en_conv) or for the Aloe vera compote (en_aloe). For all of the above dummies, 1 indicated the presence of Aloe vera or of the information provision. The same was true for the variable tasting (in both models) which was meant to control for the difference in taste of the two compotes.

Model 2 deepened the investigation into the impact of information provision and, in particular, possible saturation and/or order effects in relation to the health and environmental aspects. In this case, $X_{R}$ was a vector of two variables: treatment and tasting. Tasting (taste variable) was codified as a dummy variable that was assigned a value of 1 when respondents tasted the compote (in groups G3 and G4), and 0 otherwise (in groups G1 and G2). The "treatment" was codified through five dummy variables describing the six treatments: (i) when the WTP was elicited for the fruit-only compote, (ii) for the Aloe vera fruit compote with no additional information (Round 1), (iii) for the Aloe vera fruit compote with only the health-related information (Round 2 for G1 and G3), (iv) for the Aloe vera fruit compote with only the environment-related information (Round 2 for G2 and G4), (v) for the Aloe vera fruit compote with the health-related information plus the environmental information-in this order (Round 3 for G1 and G3), and (vi) for the Aloe vera fruit compote having received both types of information, but in the opposite order (Round 3 for G2 and G4). This new set of variables allowed us to evaluate ceteris paribus the willingness to pay across the different treatments. As before, we coded 1 when the condition was verified and 0 when it was not.

Finally, we used the delta method to verify via hypothesis tests whether the coefficients that emerged and their differences were statistically different from one other. All analyses were performed using Stata 15.

\section{Results}

Data were first analyzed via descriptive statistics. In particular, we have reported mean, standard deviation, and extreme values for the elicited willingness to pay for the two types of compote in the different experimental conditions (Table 2). What emerged is that the WTP for the aloe compote was always greater that for the conventional fruit-only compote. Moreover, the WTP for the enriched compote increased as more information on the positive properties of Aloe vera was given, i.e., from Round 1 to Round 2, and from Round 2 to Round 3 in all cases. However, there seemed to be a greater 
increase in average WTP when the information regarded health, at least when the first information was provided.

Table 2. Descriptive statistics of elicited willingness to pay for the two compotes in the different experimental conditions.

\begin{tabular}{|c|c|c|c|c|c|c|c|}
\hline Variable & Experimental Condition & Round & Obs & Mean & Std. Dev. & Min & Max \\
\hline WTP_conv & No information & 1 & 112 & 6.0 & 1.3 & 2 & 9 \\
\hline WTP_aloe & No information & 1 & 112 & 8.1 & 1.8 & 4 & 13 \\
\hline WTP_conv & Health information & 2 & 60 & 6.2 & 1.3 & 3.5 & 9 \\
\hline WTP_conv & Environmental information & 2 & 52 & 5.9 & 1.1 & 3 & 8 \\
\hline WTP_aloe & Health information & 2 & 60 & 9.9 & 2.1 & 6 & 15.5 \\
\hline WTP_aloe & Environmental information & 2 & 52 & 9.2 & 1.9 & 6 & 15 \\
\hline WTP_conv & Environmental + health information & 3 & 52 & 6.0 & 1.3 & 3 & 8.5 \\
\hline WTP_conv & Health + environmental information & 3 & 60 & 6.2 & 1.4 & 3.5 & 9.5 \\
\hline WTP_aloe & Environmental + health information & 3 & 52 & 10.1 & 2.2 & 6 & 15.5 \\
\hline WTP_aloe & Health + environmental information & 3 & 60 & 11.0 & 2.2 & 7 & 15.5 \\
\hline
\end{tabular}

Notes: In this table we report the descriptive statistics of the willingness to pay (WTP) elicited for the two compotes (conventional fruit-only compote and aloe-enriched compote) in the different treatment conditions. The treatments differed in information provision. The information the subjects were given is reported in the second column. WTPs are measured in euros for a $250 \mathrm{~g}$ jar.

To further investigate the impacts of information and other variables on the willingness to pay for the fruit compotes, we applied a set of regression models. Table 3 reports the results of the first model, while Table 4 presents the results of the second model.

Table 3. Tobit model with random effect for the WTP for the fruit compote (Model 1).

\begin{tabular}{ccccc}
\hline WTP & Coef. & & Std. Err. & p-Value \\
\hline aloe & 1.82 & $* * *$ & 0.37 & 0.000 \\
h_aloe & 1.94 & $* * *$ & 0.29 & 0.000 \\
en_aloe & 1.80 & $* * *$ & 0.41 & 0.000 \\
h_conv & -0.22 & & 0.29 & 0.422 \\
en_conv & -0.18 & & 0.41 & 0.666 \\
taste & -0.27 & & 0.32 & 0.402 \\
younger & -0.81 & $* *$ & 0.33 & 0.013 \\
older & -0.06 & & 0.29 & 0.835 \\
male & -0.63 & $* * *$ & 0.18 & 0.001 \\
1_income & -0.10 & & 0.23 & 0.639 \\
h_income & 1.00 & $* * *$ & 0.18 & 0.000 \\
diploma & -0.04 & & 0.32 & 0.894 \\
bachelor & 0.19 & & 0.35 & 0.582 \\
university & 0.32 & & 0.37 & 0.379 \\
unemployed & -0.69 & $* *$ & 0.30 & 0.024 \\
knowledge & 0.57 & & 0.35 & 0.108 \\
_cons & 6.37 & & 0.42 & 0.000 \\
Obs. & 672 & & & \\
Prob $>$ chi2 & 0.000 & & & \\
LR test of sigma_u $=0$ & 0.000 & & &
\end{tabular}

Significance levels: ${ }^{* * *} p \leq 0.01 ;{ }^{* *} 0.01<p \leq 0.05$. Notes: Reference categories: age between 30 and 40 ; income level between $€ 2000-5000$; lowest education level (middle school). This table reports the estimated coefficients, standard errors, and related $p$-values associated with all the independent variables included in Model 1 . The model applied was a random effect Tobit model censored between $€ 2$ and $€ 18$ investigating the willingness to pay (WTP) for the fruit compote depending on its attributes (e.g., with/without Aloe vera; with/without the health and/or environmental information). 
Table 4. Tobit model with random effect for the WTP for the fruit compote (Model 2).

\begin{tabular}{ccccc}
\hline WTP & Coef. & & Std. Err. & p-Value \\
\hline Treatment & & & & \\
aloe_no info & 1.78 & $* * *$ & 0.36 & 0.000 \\
aloe_health info & 3.40 & $* * *$ & 0.37 & 0.000 \\
aloe_env info & 2.87 & $* * *$ & 0.37 & 0.000 \\
aloe_health+env & 4.47 & $* * *$ & 0.37 & 0.000 \\
aloe_env+health & 4.54 & $* * *$ & 0.37 & 0.000 \\
taste & -0.25 & & 0.31 & 0.427 \\
Control variables & & & & \\
younger & 0.03 & & 0.23 & 0.876 \\
older & 0.06 & & 0.19 & 0.761 \\
male & -0.15 & & 0.14 & 0.288 \\
1_income & -0.05 & & 0.18 & 0.775 \\
h_income & 0.08 & & 0.15 & 0.576 \\
diploma & -0.05 & & 0.25 & 0.852 \\
bachelor & -0.14 & & 0.27 & 0.592 \\
university & 0.06 & & 0.28 & 0.816 \\
unemployed & -0.05 & & 0.23 & 0.826 \\
knowledge & 0.60 & $*$ & 0.35 & 0.084 \\
_cons & 6.10 & & 0.31 & 0.000 \\
Obs. & 672 & & & \\
Prob $>$ chi2 & 0.000 & & & \\
LR test of sigma_u $=0$ & 0.000 & & &
\end{tabular}

Significance levels: ${ }^{* * *} p \leq 0.01 ;{ }^{*} 0.05<p<0.1$. Notes: This table reports the estimated coefficients, standard errors, and related $p$-values associated with all the independent variables included in Model 2. The model applied was a random effect Tobit model censored between $€ 2$ and $€ 18$ investigating the willingness to pay (WTP) for the fruit compote compared to the Aloe-vera-enriched one in the different treatment conditions.

What emerged from the results of Model $1 \mathrm{~m}$ reported in Table 3, was that the presence of aloe induced a higher willingness to pay for the fruit compote (confirming H.1). Moreover, providing information on the health benefits of Aloe vera did not significantly affect the willingness to pay of the conventional fruit compote, but it did significantly increase the willingness to pay for the Aloe-vera-enriched compote. Similarly, the provision of the environmental message also did not impact the valuation for the conventional compote, but it increased that for the enriched one (confirming H.2). Tasting the compote with Aloe vera did not seem to have a significant effect. Among the individual characteristics, younger respondents seem to value the product less than older ones. Table 3 also indicates that the predicted value of willingness to pay for male respondents was lower compared to that of women. Similar results were found for unemployed consumers. Respondents with higher levels of income were found to have a higher estimated WTP.

The results reported in Table 4 confirmed the strong role of the presence of Aloe vera and information provision on the willingness to pay. Indeed, compared to the conventional fruit-only compote, adding Aloe vera significantly increased the WTP (confirming H.1). Providing one set of information on either the health benefits or the low environmental impact also significantly increased the WTP for the Aloe-vera-enriched compote (confirming H.2). The health message showed a higher coefficient and a greater increase compared to the no information treatment (Table 4). The difference was confirmed statistically by the hypothesis test reported in Table 5 (confirming H.3). 
Table 5. Hypothesis testing on the statistical difference among Model 2 regression coefficients $\beta$.

\begin{tabular}{|c|c|c|c|c|}
\hline Test & \multicolumn{2}{|c|}{ Coef. } & Std. Err. & p-Value \\
\hline$\beta$ Aloe_Health Info - $\beta$ Aloe_No Info (Test H.2) & 1.63 & $* * *$ & 0.12 & 0.000 \\
\hline$\beta$ Aloe_env info - $\beta$ Aloe_no info (test H.2) & 1.10 & $* * *$ & 0.13 & 0.000 \\
\hline $\begin{array}{c}\text { ( } \beta \text { Aloe_health info }-\beta \text { Aloe_no info) }-(\beta \text { Aloe_env info - } \\
\beta \text { Aloe_no info) }(\text { test H.3) }\end{array}$ & 0.53 & $* * *$ & 0.16 & 0.001 \\
\hline $\begin{array}{c}(\beta \text { Aloe_env }+ \text { health }-\beta \text { Aloe_env info })-(\beta \text { Aloe_health }+ \\
\text { env }-\beta \text { Aloe_health info) }\end{array}$ & 0.50 & $* * *$ & 0.18 & 0.006 \\
\hline $\begin{array}{c}\text { ( } \beta \text { Aloe_env info }-\beta \text { Aloe_no info) }-(\beta \text { Aloe_health }+ \text { env - } \\
\beta \text { Aloe_health info) }(\text { test H.4) }\end{array}$ & -0.06 & & 0.17 & 0.701 \\
\hline $\begin{array}{c}\text { ( } \beta \text { Aloe_health info - } \beta \text { Aloe_no info) }-(\beta \text { Aloe_env }+ \\
\text { health - } \beta \text { Aloe_env info) }(\text { test H.4) }\end{array}$ & -0.04 & & 0.17 & 0.804 \\
\hline$(\beta$ Aloe_health + env $-\beta$ Aloe_env + health) $($ test H.5) & 0.03 & & 0.15 & 0.859 \\
\hline
\end{tabular}

Significance levels: ${ }^{* * *} p \leq 0.01$. Notes: Tests were performed using the delta method on the regression coefficients $\beta$ derived from Model 2. The model is reported in Equation (1) (Section 2.5), while the estimated regression coefficients are shown in Table 4.

Moving to Round 3 of the experiment, i.e., when an additional informational message was provided, we found that, again, both types of additional information increased the WTP for the Aloe-vera-enriched compote (Table 4). Again, the increase was higher when the message regarded the health benefits compared to the low environmental message (confirming H.3).

Moreover, when we tested the differences between the two health-information-related increases in WTP, we found that they were not significantly different from each other (Table 5). A similar result was found for the environmental messages. Thus, there seemed not to be a diminishing return for the additional information provided nor an amplification of the informational effect; instead, the two effects seem to be additive (confuting H.4).

Furthermore, the final WTP was the same whether the health information was given before or after the environmental information. Indeed, the two coefficients associated with "full" information provision (associated with the variables "aloe_health + env" and "aloe_env + health" in Table 4) were not statistically different from each other (as emerging from Table 5). Thus, the order in which the information was provided did not seem to influence the consumer evaluation of the product elicited as the willingness to pay for it (confuting H.5).

Furthermore, the results reported in Table 4 also indicated that previous knowledge about Aloe vera may have had a positive significant effect on the willingness to pay for the Aloe-vera-enriched compote.

Table 5 reports the results of the seven hypothesis tests that used the delta method to test whether the regression coefficients $\beta$ (or some combinations of these) emerging from Model 2 (Table 4) were statistically different from each other.

\section{Discussion}

The presented results lead to several interpretations and implications for practice. First of all, without considering the effect of information, adding a food ingredient such as Aloe vera increased the WTP for the fruit compote. This result suggests that the new ingredient changed the reference price thinking of the potential consumer [47]. The absolute value of the price change, which was about $€ 2$, also suggested that the product had the potential to move away from the fruit compote category to a "functional" food category. Therefore, it seems that the attribute Aloe vera was already perceived as a quality-enhancing attribute, independently of the level of knowledge of the product itself. This introduces a first implication for management: It appears that enhancing an existing product with the Aloe vera ingredient might result in a concrete repositioning of the product within its category or even move the product to a different category.

Although Aloe vera was perceived to be a quality attribute, the results suggest that there was no full awareness and understanding of its properties. Providing new information significantly increased the WTP for the enriched compote. This increase was significant for both health and 
environmental-friendliness-based benefits, with the health message leading to a higher WTP as compared to the environmental one. These results confirmed findings highlighting the higher impact of healthiness attributes on motives or WTP of functional food choice $[5,24,27]$ and, more generally, of food categories $[48,49]$. Low price, taste, and health food attributes are usually seen as better driving food choices compared to environmental ones, because they rely on egoistic motives rather than altruistic ones $[40,50,51]$. Similarly, in the organic food category, a large body of literature shows that motives for the purchase of organic products are linked mainly to taste and health attributes, and less to environmental aspects $[50,52,53]$. The importance of egoistic vs. altruistic factors also depends on consumer segments, with the more "conscious" cluster giving additional weight to environmental dimensions [38].

Literature assessing the combined effect of health and environmental messages is scarce. Hoek et al. [36] used a hypothetical choice experiment to investigate the effect of prices and health/environmental logos and information at the point of purchase. Their results emphasized that the effect was very dependent on the consumer segment and on the similarity between standard and alternative products. However, when products were similar, results showed that the combination of health and the environment had a larger effect than when considered independently. The remaining literature has focused more on the potential synergies between healthiness and sustainability attributes, where environmental friendliness attributes could be health-driven and vice versa [40]. For example, Verain et al. [38] highlighted how the perception of healthiness could be increased by a sustainability attribute. They explained it by referring to the so-called halo effect, which is a positive effect on a quality aspect originating from a positive perception of an unrelated attribute of the same product [54-56]. In terms of implications for practice and sustainability-enhancing policies, synergies generally lead to the suggestion of preferring egoistic attributes, such as health, to leverage sustainability [38]. Hoek at al. [41] suggested what they called a stealth intervention, where the communication focus remains on health as the main benefit and driver of behavioral change, and environmental friendliness is a side effect.

The presented results are in line with those of Hoek et al. [36]. They showed that a combined effect of health and environmental messages had a larger effect than messages given in insolation. Moreover, findings highlighted how health and environmental messages add up. Both effects were large in magnitude even if, as stated before, the health message had a larger impact. However, the final WTP was independent of the sequential order in which the two messages were given. It could be that both concepts supported each other in a symmetrical way, or that no synergy effect occurred at all. In any case, this result contrasted with the view that health messages should be the main drivers and opened a broader range of communications in terms of marketing strategies and policy objectives. In fact, both concepts could be leveraged and lead to the same outcome, at least in terms of WTP. This result suggests that further investigation is needed on this aspect of functional foods in order to understand the reasons behind this observation and its external validity.

Finally, it has to be noted that tasting was never significant in the presented results. This suggested that the tangible attributes of the augmented product did not significantly affect WTP decisions. The two proposed products were considered very similar, which gave a substantial advantage in identifying the effect of the information component. Controlling for taste was also important as sensorial factors appear to discriminate consumers more than preferences toward health and environment. Consumers need to make a trade-off between decisive factors such as taste and additional attributes such as health [27] or environment [40]. If taste has a neutral effect, it implies that consumers perceive the two products as homogeneous, making it is easier to create a switch from the standard product to the augmented one. Therefore, for a product like the one tested, actions in terms of product pricing could favor a replacement of the standard products with healthier and more environmentally friendly alternatives. Of course, this should consider the cost of the food ingredients, but from a policy perspective this is in line with the results of Hoek et al. [36] showing that a price subsidy for healthy and sustainable food products is effective in shifting consumer choices when products are perceived to be similar. 
The presented research also carried some limitations and areas in need of further investigation. First of all, there is a difference between stated WTP and actual behavior. Participants reported their answers in a controlled environment, which might be substantially different from the contextual situation during a purchase. Information might not be read or noticed in the same way. For this reason, natural field experiments could help to improve the external validity of this type of study. Secondly, functional foods are not a homogeneous category in the eyes of consumers [24], and results should not be generalized to the category. Moreover, the environmental and health-related information was very specific to the combination of the product and Aloe vera attribute. Again, external validity could be gained from extending the analysis to other products in the functional domain. Finally, the analysis would benefit from a larger sample that could allow the definition of different clusters of consumers and take cultural effects into account $[25,26]$. This would allow a better tailoring of marketing and policy communications as, as suggested by Verain et al. [38], health and environmental concepts do not always go hand in hand across consumer segments.

Author Contributions: Conceptualization, E.C., E.C.R., S.S., S.M. and C.S.; Data curation, M.S.; Formal analysis, E.C. and E.C.R.; Investigation, C.S.; Methodology, E.C., S.M. and C.S.; Supervision, C.S.; Writing-original draft, E.C., E.C.R., S.S. and C.S.; Writing-review \& editing, S.S.

Funding: This research received no external funding.

Acknowledgments: Authors thank Luigi Lucini and the Department for Sustainable Food Process of Università Cattolica del Sacro Cuore, Italy, for providing the fruit compotes used in this study and the information concerning, product composition, nutritional contents, and production process.

Conflicts of Interest: The authors declare no conflict of interest.

\section{Appendix A. Additional Information on the Experimental Settings}

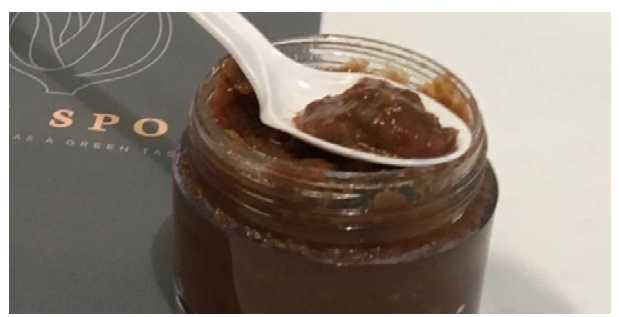

Figure A1. Fruit Compote Visual Appearance. Note: (1) visual appearance did not change between the fruit compotes (Aloe vera gel vs. pectin); (2) no specific labels were used and the jars were the same for the two products.

Table A1. Average nutritional contents of the fruit compotes used in the experiments.

\begin{tabular}{ccc}
\hline Average Nutritional Values & Per $\mathbf{1 0 0} \mathbf{g ~ ( \% ~ R I ) ~}$ & Per serving (20 g), (\% RI) \\
\hline Calories & $795 \mathrm{~kJ} / 190 \mathrm{kcal}(9.5 \%)$ & $159 \mathrm{~kJ} / 38 \mathrm{kcal}(1.9 \%)$ \\
Total fat & $0.83 \mathrm{~g}(1 \%)$ & $0.16 \mathrm{~g}(<1 \%)$ \\
Saturated fat & $0 \mathrm{~g}(0 \%)$ & $0 \mathrm{~g}(0 \%)$ \\
Total carbohydrate & $39.7 \mathrm{~g}(15 \%)$ & $7.94 \mathrm{~g}(3 \%)$ \\
Sugars & $36.97 \mathrm{~g}(41 \%)$ & $7.4 \mathrm{~g}(8 \%)$ \\
Dietary fibre & $4 \mathrm{~g}$ & $0.8 \mathrm{~g}$ \\
Protein & $3.87 \mathrm{~g}(8 \%)$ & $0.77 \mathrm{~g}(1 \%)$ \\
Sodium & $1.01 \mathrm{mg}(<1 \%)$ & $0.202 \mathrm{mg}(<1 \%)$ \\
\hline
\end{tabular}

Source: elaborations of the nutritional lab of Department for Sustainable Food Process, Università Cattolica del Sacro Cuore, Italy. Note: (1) this information was available during the experiment but not provided to participants unless explicitly requested; (2) if asked, to better control for the effect of information, the nutritional contents of the two fruit compotes were generically stated to be "similar"; (3) only a few participants asked this information and only at the end of the experiment. 
Table A2. Experimental Conditions.

\begin{tabular}{cccccc}
\hline & & & \multicolumn{2}{c}{ Treatment Name } \\
\hline & & G1 & G2 & G3 & G4 \\
\hline \multirow{3}{*}{ Information provided } & Round 1 & No info & No info & No info & No info \\
& Round 2 & Health & Environment & Health & Environment \\
& Round 3 & Environment & Health & Environment & Health \\
\hline Taste & & No & No & Yes & Yes \\
\hline Participants (n) & & 30 & 30 & 30 & 22 \\
\hline
\end{tabular}

\section{Appendix B. Fruit Compote Composition and Production}

AloeSpoon is made of Aloe vera gel (40\%), Sultanina grape (30\%), plums (27.5\%), and orange peel (2.5\%). The product only contains the sugars that are naturally present in the fruits used in the production process. Aloe gel contains between $97.5 \%$ and $98.5 \%$ water, followed by beta-polysaccharides; therefore, the caloric value of Aloe vera gel is very low and the consumption of one serving (about $200 \mathrm{~mL}$ ) of gel contributes less than $5 \mathrm{kcal}$. The biggest intake of simple sugars is provided by Sultanina grape: it is a dehydrated food, so it has a low water content and is a real nutritional and caloric concentrate, in particular because of its high fructose content. Finally, the presence of orange peels allowed several goals to be achieved including a better taste, given that Aloe vera tastes naturally bitter.

The production process includes fruit mixing and concentration under heating until the desired level of Brix, measured by refractometer, is reached. Aloe barbadensis Mill. gel is then added. The final compote is dosed in the jar, pasteurized, and cooled to ensure the creation of vacuum. The product can be stocked at room temperature.

\section{References}

1. Rousseau, S. The role of organic and fair trade labels when choosing chocolate. Food Qual. Prefer. 2015, 44, 92-100. [CrossRef]

2. Grunert, K.G.; Hieke, S.; Wills, J. Sustainability labels on food products: Consumer motivation, understanding and use. Food Policy 2014, 44, 177-189. [CrossRef]

3. Del Giudice, T.; Stranieri, S.; Caracciolo, F.; Ricci, E.C.; Cembalo, L.; Banterle, A.; Cicia, G. Corporate Social Responsibility certifications influence consumer preferences and seafood market price. J. Clean. Prod. 2018, 178, 526-533. [CrossRef]

4. Annunziata, A.; Vecchio, R. Consumer perception of functional foods: A conjoint analysis with probiotics. Food Qual. Prefer. 2013, 28, 348-355. [CrossRef]

5. Szakály, Z.; Kovács, S.; Peto, K.; Huszka, P.; Kiss, M. A modified model of the willingness to pay for functional foods. Appetite 2019, 138, 94-101. [CrossRef]

6. Martirosyan, D.M.; Singh, J. A new definition of functional food by FFC: What makes a new definition unique? Funct. Foods Health Dis. 2015, 5, 209-223.

7. Diplock, A.; Aggett, P.; Ashwell, M.; Bornet, F.; Fern, E.; Robertfroid, M. Scientific concepts of functional foods in Europe: Consensus document. Br. J. Nutr. 1999, 81, 1-27.

8. Poulsen, J. Danish Consumers' Attitudes Towards Functional Foods; University of Aarhus, Aarhus School of Business, The MAPP Centre: Aarhus, Denmark, 1999.

9. Siegrist, M.; Stampfli, N.; Kastenholz, H. Consumers' willingness to buy functional foods. The influence of carrier, benefit and trust. Appetite 2008, 51, 526-529. [CrossRef]

10. Frewer, L.; Scholderer, J.; Lambert, N. Consumer acceptance of functional foods: Issues for the future. Br. Food J. 2003, 105, 714-731. [CrossRef]

11. Labrecque, J.; Doyon, M.; Bellavance, F.; Kolodinsky, J. Acceptance of functional foods: A comparison of French, American, and French Canadian consumers. Can. J. Agric. Econ. Rev. Can. D'agroecon. 2006, 54, 647-661. [CrossRef]

12. Urala, N.; Lähteenmäki, L. Consumers' changing attitudes towards functional foods. Food Qual. Prefer. 2007, 18, 1-12. [CrossRef] 
13. Niva, M. 'All foods affect health': Understandings of functional foods and healthy eating among health-oriented Finns. Appetite 2007, 48, 384-393. [CrossRef] [PubMed]

14. Ares, G.; Gámbaro, A. Influence of gender, age and motives underlying food choice on perceived healthiness and willingness to try functional foods. Appetite 2007, 49, 148-158. [CrossRef] [PubMed]

15. Annunziata, A.; Vecchio, R. Functional foods development in the European market: A consumer perspective. J. Funct. Foods 2011, 3, 223-228. [CrossRef]

16. Bhaskaran, S.; Hardley, F. Buyer beliefs, attitudes and behaviour: Foods with therapeutic claims. J. Consum. Mark. 2002, 19, 591-606. [CrossRef]

17. Verbeke, W. Consumer acceptance of functional foods: Socio-demographic, cognitive and attitudinal determinants. Food Qual. Prefer. 2005, 16, 45-57. [CrossRef]

18. Wansink, B.; Westgren, R.E.; Cheney, M.M. Hierarchy of nutritional knowledge that relates to the consumption of a functional food. Nutrition 2005, 21, 264-268. [CrossRef]

19. Ricci, E.C.; Stranieri, S.; Casetta, C.; Soregaroli, C. Consumer preferences for Made in Italy food products: The role of ethnocentrism and product knowledge. AIMS Agric. Food 2019, 4, 88-110. [CrossRef]

20. Cox, D.N.; Koster, A.; Russell, C.G. Predicting intentions to consume functional foods and supplements to offset memory loss using an adaptation of protection motivation theory. Appetite 2004, 43, 55-64. [CrossRef]

21. Huotilainen, A.; Seppälä, T.; Pirttilä-Backman, A.M.; Tuorila, H. Derived attributes as mediators between categorization and acceptance of a new functional drink. Food Qual. Prefer. 2006, 17, 328-336. [CrossRef]

22. Korzen-Bohr, S.; Jensen, K.O. Heart disease among post-menopausal women: Acceptability of functional foods as a preventive measure. Appetite 2006, 46, 152-163. [CrossRef] [PubMed]

23. Urala, N.; Lähteenmäki, L. Attitudes behind consumers' willingness to use functional foods. Food Qual. Prefer. 2004, 15, 793-803. [CrossRef]

24. Krystallis, A.; Maglaras, G.; Mamalis, S. Motivations and cognitive structures of consumers in their purchasing of functional foods. Food Qual. Prefer. 2008, 19, 525-538. [CrossRef]

25. Siegrist, M.; Shi, J.; Giusto, A.; Hartmann, C. Worlds apart. Consumer acceptance of functional foods and beverages in Germany and China. Appetite 2015, 92, 87-93. [CrossRef] [PubMed]

26. Pappalardo, G.; Lusk, J.L. The role of beliefs in purchasing process of functional foods. Food Qual. Prefer. 2016, 53, 151-158. [CrossRef]

27. Verbeke, W. Functional foods: Consumer willingness to compromise on taste for health? Food Qual. Prefer. 2006, 17, 126-131. [CrossRef]

28. Ares, G.; Giménez, A.; Gámbaro, A. Consumer perceived healthiness and willingness to try functional milk desserts. Influence of ingredient, ingredient name and health claim. Food Qual. Prefer. 2009, 20, 50-56. [CrossRef]

29. Williams, P.; Ridges, L.; Batterham, M.; Ripper, B.; Hung, M.C. Australian consumer attitudes to health claim-food product compatibility for functional foods. Food Policy 2008, 33, 640-643. [CrossRef]

30. Van Kleef, E.; van Trijp, H.C.; Luning, P. Functional foods: Health claim-food product compatibility and the impact of health claim framing on consumer evaluation. Appetite 2005, 44, 299-308. [CrossRef]

31. Marette, S.; Roosen, J.; Blanchemanche, S.; Feinblatt-Mélèze, E. Functional food, uncertainty and consumers' choices: A lab experiment with enriched yoghurts for lowering cholesterol. Food Policy 2010, 35, 419-428. [CrossRef]

32. Horne, R.E. Limits to labels: The role of eco-labels in the assessment of product sustainability and routes to sustainable consumption. Int. J. Consum. Stud. 2009, 33, 175-182. [CrossRef]

33. Nash, H.A. The European Commission's sustainable consumption and production and sustainable industrial policy action plan. J. Clean. Prod. 2009, 17, 496-498. [CrossRef]

34. Tobler, C.; Visschers, V.H.M.; Siegrist, M. Eating green. Consumers' willingness to adopt ecological food consumption behaviors. Appetite 2011, 57, 674-682. [CrossRef] [PubMed]

35. Goetzke, B.; Nitzko, S.; Spiller, A. Consumption of organic and functional food. A matter of well-being and health? Appetite 2014, 77, 96-105. [CrossRef]

36. Hoek, A.C.; Pearson, D.; James, S.W.; Lawrence, M.A.; Friel, S. Healthy and environmentally sustainable food choices: Consumer responses to point-of-purchase actions. Food Qual. Prefer. 2017, 58, 94-106. [CrossRef]

37. Banterle, A.; Ricci, E.C.; Cavaliere, A. Environmental sustainability and the food system. In Regulating and Managing Food Safety in the EU-A Legal-Economic Perspective; Bremmers, H.J., Purnhagen, K., Eds.; Springer International Publishing: Cham, Switzerland, 2018. 
38. Verain, M.C.; Sijtsema, S.J.; Antonides, G. Consumer segmentation based on food-category attribute importance: The relation with healthiness and sustainability perceptions. Food Qual. Prefer. 2016, 48, 99-106. [CrossRef]

39. Banterle, A.; Stranieri, S. Sustainability standards and the reorganization of private label supply chains: A transaction cost perspective. Sustainability 2013, 5, 5272-5288. [CrossRef]

40. Aschemann-Witzel, J. Consumer perception and trends about health and sustainability: Trade-offs and synergies of two pivotal issues. Curr. Opin. Food Sci. 2015, 3, 6-10. [CrossRef]

41. Hoek, A.C.; Pearson, D.; James, S.W.; Lawrence, M.A.; Friel, S. Shrinking the food-print: A qualitative study into consumer perceptions, experiences and attitudes towards healthy and environmentally friendly food behaviours. Appetite 2017, 108, 117-131. [CrossRef]

42. Sahu, P.K.; Giri, D.D.; Singh, R.; Pandey, P.; Gupta, S.; Shrivastava, A.K.; Kumar, A.; Pandey, K.D. Therapeutic and medicinal uses of Aloe vera: A review. Pharmacol. Pharm. 2013, 4, 599. [CrossRef]

43. Andersen, S.; Harrison, G.W.; Lau, M.I.; Rutström, E.E. Elicitation using multiple price list formats. Exp. Econ. 2006, 9, 383-405. [CrossRef]

44. Castellari, E.; Marette, S.; Moro, D.; Sckokai, P. The Impact of Information on Willingness to Pay and Quantity Choices for Meat and Meat Substitute. J. Agric. Food Ind. Organ. 2018, 17. [CrossRef]

45. Wansink, B.; Sonka, S.T.; Hasler, C.M. Front-label health claims: When less is more. Food Policy 2004, 29, 659-667. [CrossRef]

46. Anderson, S.; Harrison, G.W.; Lau, M.I.; Elisabet, R.E. Valuation using multiple price list formats. Appl. Econ. 2007, 39, 675-682. [CrossRef]

47. Mazumdar, T.; Raj, S.P.; Sinha, I. Reference price research: Review and propositions. J. Mark. 2005, 69, 84-102. [CrossRef]

48. Markovina, J.; Stewart-Knox, B.J.; Rankin, A.; Gibney, M.; de Almeida, M.D.V.; Fischer, A.; Kuznesof, S.A.; Poínhos, R.; Panzone, L.; Frewer, L.J. Food4Me study: Validity and reliability of Food Choice Questionnaire in 9 European countries. Food Qual. Prefer. 2015, 45, 26-32. [CrossRef]

49. Sautron, V.; Péneau, S.; Camilleri, G.M.; Muller, L.; Ruffieux, B.; Hercberg, S.; Méjean, C. Validity of a questionnaire measuring motives for choosing foods including sustainable concerns. Appetite 2015, 87, 90-97. [CrossRef]

50. Magnusson, M.K.; Arvola, A.; Hursti, U.K.K.; AAberg, L.; Sjödén, P.O. Choice of organic foods is related to perceived consequences for human health and to environmentally friendly behaviour. Appetite 2003, 40, 109-117. [CrossRef]

51. Stranieri, S.; Baldi, L. Shelf Life Date Extension of Fresh-Cut Salad: A Consumer Perspective. J. Food Prod. Mark. 2017, 23, 939-954. [CrossRef]

52. Gracia, A.; De Magistris, T. The demand for organic foods in the South of Italy: A discrete choice model. Food Policy 2008, 33, 386-396. [CrossRef]

53. Chryssohoidis, G.M.; Krystallis, A. Organic consumers' personal values research: Testing and validating the list of values (LOV) scale and implementing a value-based segmentation task. Food Qual. Prefer. 2005, 16, 585-599. [CrossRef]

54. Richetin, J.; Demartini, E.; Gaviglio, A.; Ricci, E.C.; Stranieri, S.; Banterle, A.; Perugini, M. The biasing effect of evocative attributes at the implicit and explicit level: The tradition halo and the industrial horn in food products evaluations. J. Retail. Consum. Serv. 2019, 101890. [CrossRef]

55. Nisbett, R.E.; Wilson, T.D. The halo effect: Evidence for unconscious alteration of judgments. J. Pers. Soc. Psychol. 1977, 35, 250. [CrossRef]

56. Demartini, E.; Ricci, E.C.; Mattavelli, S.; Stranieri, S.; Gaviglio, A.; Banterle, A.; Richetin, J.; Perugini, M. Exploring Consumer Biased Evaluations: Halos Effects of Local Food and of Related Attributes. Int. J. Food Syst. Dyn. 2018, 9, 375-389.

(C) 2019 by the authors. Licensee MDPI, Basel, Switzerland. This article is an open access article distributed under the terms and conditions of the Creative Commons Attribution (CC BY) license (http://creativecommons.org/licenses/by/4.0/). 